\title{
A pós-graduação como estratégia de reconstrução da Universidade Brasileira
}

\section{The postgraduate studies with strategy for the reconstruction of the Brazilian university system}

\author{
Ana Waleska Pollo Campos Mendonça**
}

\begin{abstract}
RESUMO
Este trabalho se relaciona com a pesquisa A formação dos mestres: a contribuição de Anísio Teixeira para a institucionalização da pós-graduação no Brasil, que examina a política desenvolvida pelo educador brasileiro Anísio Teixeira na direção da CAPES (Campanha de Aperfeiçoamento do Pessoal de Nível Superior), atualmente uma fundação vinculada ao Ministério da Educação, em seus primeiros anos de funcionamento (19511964).

Trata-se de uma pesquisa histórica que tem como seu corpus documental básico:

a) a produção bibliográfica de Anísio Teixeira, de 1946 a 1971;

b) a documentação existente nos arquivos da CAPES e no arquivo pessoal de Anísio Teixeira, no Centro de Investigação e Documentação em História Contemporânea do Brasil, na Fundação Getúlio Vargas e no Programa de Estudos e Documentação Educação e Sociedade, da Universidade Federal do Rio de Janeiro;

c) os boletins da CAPES publicados, mensalmente, de 1952 a 1964;

d) entrevistas realizadas com antigos colaboradores de Anísio Teixeira na CAPES, durante o período estudado.
\end{abstract}

Conferência proferida na aula inaugural da primeira turma de doutorado do Programa de Pós-Graduação em Educação da Universidade Federal do Paraná, no ano de 2002.

** Doutora em Educação. Professora Associada da Pontifícia Universidade Católica do Rio de Janeiro (PUC-Rio). E-mail: awm@edu.puc-rio.br 
Os resultados da pesquisa confirmam nossa hipótese inicial que a atuação de Anísio Teixeira frente a esta instituição foi fundamental para que ela adquirisse a configuração que assumiu, transformando-se em um instrumento de promoção dos estudos de pós-graduação no Brasil. Sob este prisma, a CAPES desenvolveu, em seus primeiros anos, um conjunto de iniciativas e políticas que tiveram como pressuposto básico a idéia de que a pós-graduação era a principal estratégia de reconstrução da universidade brasileira, como lócus adequado para o desenvolvimento da pesquisa científica e como espaço de formação do professor universitário.

Palavras-chave: Universidade Brasileira, pós-graduação, Anísio Teixeira.

\begin{abstract}
This article is the result of a research project entitled "The Training of Teachers: the Contribution of Anísio Teixeira for the Institutionalization of Postgraduate Studies in Brazil" (A formação dos mestres: a contribuição de Anísio Teixeira para a institucionalização da pós-graduação no Brasil), which analyzed the policies developed by the Brazilian educator Anísio Teixeira, while acting as head of CAPES - Campaign for the Improvement of University Personnel (Campanha de Aperfeiçoamento do Pessoal de Nivel Superior) - now a foundation linked to the Ministry of Education, during its initial years of operation, from 1951-1964.

The research is historical, its basic corpus of documents being:

a) texts published by Anísio Teixeira, from 1946 to 1971;

b) documents in the archives of CAPES, in the personal archives of Anísio Teixeira, in the Centre for Research and Documentation in Contemporary Brazilian History, at the Getúlio Vargas Foundation, and in the Programme of Studies and Documentation in Education and Society, at the Federal University of Rio de Janeiro;

c) the Bulletins of CAPES, published monthly from 1952 to 1964;

d) interviews with contemporary collaborators of Anísio Teixeira, in CAPES, during the period studied.

The results of the research confirm our initial hypothesis, that the role of Anísio Teixeira at the head of this institution was fundamental in giving it the form and function it ended up assuming, turning it into an instrument for the promotion of postgraduate studies in Brazil. Within this perspective, CAPES developed, in its initial years, a set of initiatives and policies which had, as a basic presupposition, the idea that postgraduate study should constitute the principal strategy for the reconstruction of the Brazilian university system, as an adequate locus for the development of scientific research and as a space for the education of university professors.

Key-words: Brazilian University, postgraduate studies, Anísio Teixeira.
\end{abstract}




\section{Anísio Teixeira e a pós-graduação no Brasil}

Este texto remete à pesquisa $A$ formação dos mestres: a contribuição de Anísio Teixeira para a institucionalização da pós-graduação no Brasil ${ }^{1}$, recentemente concluída, que teve como objetivo geral estudar a contribuição do educador brasileiro no referido processo, ao longo dos anos 1950/1960. Foi ao longo desses anos (especificamente, de 1951 a 1964) que Anísio Teixeira, como Secretário Geral da CAPES, atual Fundação de Aperfeiçoamento do Pessoal de Nível Superior, criada inicialmente sob a forma de Campanha ${ }^{2}$, organizou a entidade, estabelecendo as bases para a surpreendente expansão que o ensino de pós-graduação viria a ter entre nós, particularmente após os anos 1970.

A Campanha Nacional de Aperfeiçoamento de Pessoal de Nível Superior foi, de início, idealizada por Romulo de Almeida, economista baiano, com o objetivo de formar os quadros necessários ao programa de desenvolvimento econômico pensado pela equipe que cercava o então presidente Getúlio Vargas. Em 1951, Anísio Teixeira foi chamado por Ernesto Simões Filho, à época Ministro da Educação e Saúde, para assumir o cargo de Secretário Geral da Comissão que teria como objetivo promover a referida Campanha. Embora prevista, inicialmente, para ser instalada em seis meses, apenas dez anos depois a Campanha foi formalmente constituída, com algumas mudanças significativas nos seus objetivos, que a simples comparação entre os dois

1 Integraram a equipe da pesquisa, em diferentes momentos da sua realização, Ana Lúcia da Cunha Fernandes, Carlos Otávio Fiúza Monteiro, Maria Celi Chaves Vasconcelos, Miriam Waidenfeld Chaves (doutorandos do Programa de Pós-Graduação em Educação da PUC-Rio), Fernando César Ferreira Gouvêa, Jussara Santos Pimenta (Mestrandos do Programa de PósGraduação em Educação da PUC-Rio), Alessandra Stachuck Mello, Carolina Moreira Kimus, Flávia Santos de Oliveira, Lenilce Flor Duarte, Luciana de Paiva Ferreira de Almeida (bolsistas de Iniciação Científica do CNPq), Maria Teresa Cavalcanti de Oliveira (bolsista de Apoio Técnico da FAPERJ), Paulo Teixeira Drumond (consultor técnico). Na elaboração do relatório final da pesquisa, sobre o qual se apoia mais diretamente este texto, foi particularmente preciosa a colaboração de Maria Teresa Cavalcanti de Oliveira, Fernando César Ferreira Gouvêa e Alessandra Stachuck de Mello.

2 As campanhas extraordinárias se constituíram em uma estratégia bastante utilizada pelo Ministério da Educação durante os anos em estudo para agilizar o atendimento de determinadas metas consideradas prioritárias, contornando por um lado a inércia da burocracia estatal e garantindo, por outro, uma maior autonomia para a realização de acordos, contratos e convênios com organizações técnicas e de ensino e com especialistas externos aos quadros da burocracia ministerial. 
decretos: o Decreto n. ${ }^{\circ} 29.741$, de 11 de julho de 1951, que institui a Comissão, e o Decreto n. ${ }^{\circ}$ 50.737, de 7 de junho de 1961, que organiza a Campanha, claramente evidencia. Enquanto no primeiro decreto a ênfase recaía sobre a formação de pessoal especializado para atender às necessidades dos empreendimentos públicos e privados que visam o desenvolvimento do país, promovendo, entre outras coisas, a instalação e expansão de centros de aperfeiçoamento e estudos pós-graduados, no segundo decreto aparece como o primeiro propósito da Campanha, para a consecução dos seus objetivos, a melhoria das condições de ensino e pesquisa dos centros universitários, como estratégia prioritária para a formação dos quadros profissionais de nível superior do país.

A CAPES, aliás, teve um encaminhamento institucional bastante peculiar. Nasce por meio de uma Comissão, sob a presidência do Ministro de Educação e Saúde (MES) e com um Secretário Geral designado pelo Ministro, composta por representantes de diversas instituições públicas e privadas: além do MES, o Departamento Administrativo do Serviço Público (DASP), a Fundação Getúlio Vargas (FGV), o Banco do Brasil, a Comissão Nacional de Assistência Técnica, a Comissão Mista Brasil-Estados Unidos, o Conselho Nacional de Pesquisas (CNPq), o Instituto Brasileiro de Geografia e Estatística (IBGE), a Confederação Nacional da Indústria (CNI), a Confederação Nacional do Comércio (CNC). Importa assinalar que a composição heterogênea da Comissão é expressiva da diversidade dos interesse políticos e econômicos envolvidos no processo da sua criação. A análise dos documentos iniciais da CAPES evidencia claramente que o seu processo de institucionalização foi marcado por intensas discussões e por uma luta pela hegemonia que vão se refletir na organização e na prática da instituição. Em alguns trabalhos utilizados pela pesquisa (GUSSO, CÓRDOVA e LUNA, 1985 e CóRDOVA,1998), faz-se referência a dois grupos antagônicos que disputavam a liderança do processo: o dos pragmáticos, que tinham a sua atenção voltada para a falta de pessoal técnico qualificado para atender ao plano de reequipamento nacional e propunham medidas de caráter mais imediatista orientadas para setores da economia considerados estratégicos, e os políticos, que enxergavam na CAPES o ponto de partida para uma reforma global da universidade, entrevendo um avanço científico mais sólido, menos casuístico e mais autônomo do país. Anísio Teixeira exerceu um importante papel mediador entre os dois grupos, mas garantindo sem dúvida a hegemonia do segundo. Os dois grandes programas com os quais a CAPES se organiza desde o início são expressivos dessa tentativa de conciliação: o Programa de Quadros Técnicos e Científicos (PQTC) e o Pro- 
grama Universitário $(\mathrm{PgU})^{3}$. O primeiro, particularmente voltado para os campos da Engenharia, Química, Arquitetura, Economia, Administração, Agronomia e Veterinária, orientando o seu trabalho em uma tríplice direção: o levantamento das necessidades nacionais em termos de pessoal especializado de nível superior, o levantamento dos centros de preparação e aperfeiçoamento pós-graduado já existentes no país, com vistas à sua utilização mais ampla e racional, e a preparação e aperfeiçoamento, no Brasil e no exterior, de especialistas de cuja falta se ressentissem os quadros de pessoal do país. $\mathrm{O}$ segundo, tendo como objetivo principal estimular o desenvolvimento das universidades e institutos de ensino superior, e voltado particularmente para os campos das Ciências Biológicas, Medicina e afins, Ciências Sociais, Matemáticas e Humanidades. Propunha-se a desenvolver um plano de melhoria das condições de ensino e pesquisa dos Centros Universitários do país, utilizando-se, inclusive, do concurso de missões de professores estrangeiros, mas sempre com o objetivo de consolidação das instituições universitárias e grupos de pesquisa nacionais. Desta perspectiva, propunha-se particularmente ao desenvolvimento e aperfeiçoamento dos centros brasileiros de treinamento pós-graduado (e alimentando-se, deste ponto de vista, dos levantamentos realizados pelo $\mathrm{PQTC})$.

O longo tempo que medeia entre a criação da Comissão e a organização da Campanha é expressivo da intensidade desse debate. No entanto, desde 1952, a CAPES funciona de fato como Campanha (inclusive é essa denominação que aparece na própria publicação oficial do órgão, o Boletim da CAPES, que começa a ser editado regularmente a partir de dezembro de 1952), tendo o Instituto Nacional de Estudos Pedagógicos (INEP) como seu órgão executivo. A esse respeito, é bom lembrar que Anísio Teixeira assume também, a partir deste ano, a direção desse órgão, acumulando-a com a Secretaria Geral da CAPES.

Na nossa perspectiva, o Decreto n. $^{\circ}$ 50.737, de 7 de junho de 1961, que organiza a Campanha, consolida, em linhas gerais, uma situação já existente. É interessante, por exemplo, assinalar que, neste decreto, a Comissão da CAPES é extinta e seu lugar é ocupado por um Conselho Consultivo com uma composição semelhante, embora com algumas ausências/ alterações

3 Além desses dois Programas, a CAPEs possuía dois Serviços: o de Bolsas de Estudo (SBE) e o de Estatística e Documentação (SED), além da Seção de Administração. Era uma estrutura bastante enxuta e que tinha, no desenvolvimento de projetos, a base de organização do seu trabalho. 
significativas: representantes do Ministério da Educação e Cultura ${ }^{4}$, Ministério do Trabalho, Ministério das Relações Exteriores, CNPq, Banco Nacional de Desenvolvimento Econômico (BNDE), CNI e CNC. Anísio Teixeira se torna o coordenador da Campanha e esta passa a vincular-se diretamente à Presidência da República.

De uma forma geral, a pesquisa confirmou nossa hipótese inicial de que a atuação de Anísio Teixeira à frente da CAPES foi fundamental para dar a esse órgão a configuração que acabou assumindo, tornando-o de fato um instrumento de promoção e expansão dos estudos pós-graduados no Brasil e garantindo, inclusive, que a pesquisa científica se desenvolvesse entre nós no âmbito da universidade.

A pesquisa documental junto ao Arquivo de Anísio Teixeira no CPDOC (Centro de Pesquisa e Documentação em História Contemporânea do Brasil), da FGV, levou-nos à localização de uma série de documentos pessoais do educador referentes aos passos iniciais da Campanha, ou mesmo anteriores ao momento em que este assumiu a CAPES, que nos permitiram atribuir a Anísio Teixeira um papel central na própria gênese dessa instituição. As entrevistas de alguns dos antigos colaboradores de Anísio Teixeira nessa empreitada, que também se constituíram em parte integrante do nosso corpus documental, reforçam esse ponto de vista.

Pode-se, portanto, afirmar que a CAPES dos anos 1950/1960 se configurou como um projeto institucional que tem a marca pessoal de Anísio Teixeira, tomando-se aqui o termo projeto $^{5}$ no sentido que lhe é atribuído por CORRÊA

4 A partir de 1953, o Ministério da Educação e Saúde foi desmembrado em dois: Educação e Cultura e o da Saúde.

5 CORRÊA (1987) afirma que é a noção de projeto, mais do que as noções de instituição, corrente ou escola, que melhor consegue dar conta dos motivos que agruparam cientistas sociais em esforços coletivos de pesquisa, ao longo dos anos 40 e 50 do século passado. A noção de projeto, recorrente nos depoimentos destes cientistas, acaba por se constituir em sinônimo de grupo de referência, tornando-se o elo que articulava um determinado grupo de intelectuais em torno a uma problemática comum e expressando, sem dúvida, inclusive para eles mesmos, uma forma específica de atuação política. Esta perspectiva, a nosso ver, pode se aplicar, igualmente, a alguns projetos institucionais, que se configuraram como espaços de intervenção política de alguns desses intelectuais, no interior do aparelho de Estado, mas com uma surpreendente margem de autonomia, como é o caso da CAPES.

Por outro lado, parece-nos igualmente importante ressaltar, como afirma velHo (1994), que a noção de projeto está indissoluvelmente ligada à idéia de indivíduo-sujeito, mesmo em se tratando de um ator coletivo. Desta perspectiva, um projeto coletivo supõe sempre a imbricação de uma série de projetos individuais distintos e, algumas vezes, conflitivos, e esse fato é condicionante, no caso de uma instituição como a CAPES, da sua própria trajetória. 
(1987) e por VELHO (1994). Desta perspectiva, a CAPES desenvolveu, ao longo desses anos, um conjunto de iniciativas e de políticas, que tinham como um de seus pressupostos básicos a idéia de que a pós-graduação se constituía na principal estratégia de reconstrução ${ }^{6}$ da universidade brasileira, para adequála às necessidades do desenvolvimento nacional.

Numa dupla direção, a pós-graduação se configurava, para Anísio Teixeira, como instrumento de reconstrução da universidade brasileira.

Em primeiro lugar, constituindo-se no lócus, por excelência, do desenvolvimento da pesquisa científica, no interior da universidade, a escola pósgraduada se impunha como requisito para transformar a universidade brasileira numa universidade de ciência e de pesquisa, que fosse não apenas transmissora de um conhecimento elaborado, mas criadora de um novo saber, de um novo conhecimento, que contribuísse para a construção de uma cultura brasileira e fizesse marchar o conhecimento humano (TEIXEIRA, 1989).

Segundo Anísio Teixeira, o grande problema do ensino superior no Brasil, à época, era a inexistência de uma tradição universitária, no sentido de que, não só não tivemos entre nós a instituição universitária nos moldes em que ela existiu na Europa e, inclusive, na América Espanhola durante o período colonial, mas não teríamos sequer experimentado a universidade moderna - expressão do renascimento dessa instituição na Europa do século XIX que surge sob o signo da constituição dos Estados nacionais e da emergência do conhecimento científico (momento em que este se incorpora à universidade, já que nasce fora dos seus muros), cujo modelo mais acabado é a Universidade de Humboldt.

Remetendo-se à experiência das Faculdades de Filosofia, Ciências e Letras, lembrava Anísio Teixeira que estas, na sua origem, tiveram o objetivo de aproximar a universidade brasileira do modelo humboldtiano de pesquisa e ensino aprofundado, mas que, na prática, acabaram por se constituir, apenas, na sua maioria, em escolas normais de preparo do magistério secundário e, com poucas exceções, colégios de artes liberais (TEIXEIRA, 1989, p. 108), configurando-se, desta perspectiva, em uma experiência fracassada.

6 A respeito do termo reconstrução, cumpre destacar a preferência de Anísio por este termo, em contraposição ao termo reforma, num período - anos 1950-1970 - em que a sua utilização poderia até soar como um anacronismo. A nosso ver, essa não é uma escolha gratuita, mas é indicativa do caráter necessariamente processual (e não pontual, como o termo reforma denota) que Anísio Teixeira atribuía às mudanças que, a seu ver, se faziam necessárias implantar na educação brasileira. 
Para Anísio Teixeira, o atraso brasileiro estaria articulado à nossa situação de dependência cultural e a inexistência de uma universidade voltada para a constituição de uma cultura nacional e orientada à solução dos problemas nacionais seria, sem dúvida, o principal fator que justificaria essa situação de dependência.

A este respeito, importa destacar que Anísio Teixeira expressava, à época, uma visão cumulativa das funções da universidade, no sentido de considerar que as novas funções que se foram atribuindo historicamente a essa instituição, não eliminavam as anteriores porque não eram excludentes. Para ele, a universidade contemporânea deveria ser simultaneamente uma universidade humanista, como a universidade medieval, oferecendo, portanto, uma formação básica geral (embora de tipo radicalmente distinto da cultura medieval); uma universidade moderna, voltada para a pesquisa e a produção do conhecimento, como a universidade humboldtiana; uma universidade de serviço, como a universidade de Newman, devotada aos problemas práticos da sua sociedade e à educação; e, até, uma multiversidade, ligada à indústria e ao desenvolvimento nacional.

De um outro ponto de vista, também, a pós-graduação contribuiria nesse processo de renovação profunda da universidade brasileira. Para Anísio Teixeira, fazia-se necessário, para atender às novas exigências do desenvolvimento nacional, uma mudança de qualidade no ensino superior brasileiro, que implicava numa transformação radical das práticas efetivamente desenvolvidas no seu interior, supondo mudanças substantivas, não só nas estruturas universitárias, mas na própria mentalidade dos professores universitários.

Para ele, estava chegado o momento de se ter a escola pós-graduada como centro e cúpula da nova universidade, formulando e reformulando o saber que seria ensinado na própria universidade, formando os quadros superiores de cientistas nos vários campos do saber humano e constituindo-se no espaço por excelência de formação do professor universitário. Dessa escola partiria, para ele, a verdadeira reforma universitária que se fazia necessária, uma reforma a partir de dentro da universidade, nas suas próprias palavras .

Foi essa a orientação básica que direcionou a atuação de Anísio Teixeira à frente da CAPES. 


\section{As origens da pós-graduação no Brasil}

Em trabalho elaborado pela própria CAPES, em colaboração com o Centro Regional de Estudos Superiores para a América Latina e o Caribe (CRESALC), GUSSO, CÓRDOVA e LUNA (1985) fazem uma análise do processo de institucionalização da pós-graduação no país, que foi extremamente elucidativa para o nosso trabalho, fornecendo uma importante chave de leitura.

Alguns dos aspectos que são destacados nesta análise aproximam-se bastante da leitura que é feita por Anísio Teixeira, ao longo dos anos em estudo, desse mesmo processo. Aliás, este educador se constitui em uma das referências bibliográficas das quais os autores se servem.

Para os autores, afora as experiências dissidentes dos anos 1930 (as experiências da Universidade de São Paulo - USP e da Universidade do Distrito Federal - UDF $)^{7}$, o modelo de universidade que se firma no Brasil, ao longo dos anos 1940, e que prevalece até os anos 1960, é o modelo de universidadefederação de escolas profissionais, no qual a pesquisa científica tem um espaço bastante limitado. Sob esse paradigma, o ensino superior se expande lentamente até 1945, quando, então, o processo de expansão se acelera, sob o impacto da redemocratização do país e o notável crescimento urbano com a conseqüente ampliação dos estratos médios, mantendo-se, entretanto, num primeiro momento, o modelo.

Por esta razão, para estes autores, os estudos pós-graduados no Brasil acabam por ser gerados por movimentos predominantemente exógenos aos processos que movem o sistema de ensino superior (GUSSO, CÓRDOVA e LUNA, 1985, p. 177). Para eles:

...a gênese dos estudos pós-graduados se confunde, em primeiro lugar, com as lutas pela formação da comunidade científica brasileira, e pela constituição dos seus espaços institucionais; e só mais tarde se entrelaça à Universidade com o surgimento da consciência de que o País se embaraçava nas teias da dependência tecnológica.

7 A esse respeito, ver a minha tese de Doutorado, recentemente publicada (MENDONÇA, 2002). 
Na percepção dos mesmos, a hegemonia do modelo se justificava pelo fato de que correspondia não só aos objetivos atribuídos pela sociedade brasileira ao ensino superior, mas às próprias expectativas das camadas da população que tinham acesso a esse nível de ensino.

Com o desenvolvimentismo dos anos 1950, este paradigma começa a entrar em crise, face ao avanço do processo de industrialização, bem como às mudanças que estão ocorrendo nos canais de ascensão social e a questão da reforma da universidade se coloca com uma certa urgência. No entanto, as forças de resistência são muitas e se localizam, principalmente, para os autores, na própria burocracia estatal e nas lideranças conservadoras do Congresso, fazendo com que nenhum projeto mais abrangente de reforma da universidade seja encaminhado nesta década.

Por outro lado, a comunidade científica crescera, desenvolvera a sua organização e adquirira maior articulação política, principalmente com a criação da Sociedade Brasileira pelo Progresso da Ciência (SBPC) e do Centro Brasileiro de Pesquisas Físicas (CBPF). No âmbito da SBPC, começa a se desenvolver uma vertente de pensamento mais política (e até mesmo, nacionalista) no seio da comunidade científica brasileira ${ }^{8}$.

Uma outra vertente de pensamento, mais pragmática, nascia de outros grupos da burocracia estatal e das escolas técnicas superiores. Seus objetivos eram mais imediatistas e a perspectiva nacionalista estava totalmente ausente das suas preocupações. Uma das principais iniciativas desse grupo se expressou na criação da COSUPI ( Comissão Supervisora do Plano dos Institutos) ${ }^{9}$, que sofreu a oposição da SBPC que se posicionou contra a dispersão de recursos provocada pelo programa e contra a sua orientação especialista, bem como contra a política de concentrar em institutos isolados a pesquisa científica, desestimulando os núcleos já consolidados nas faculdades e organismos científicos mais apropriados.

A primeira vertente é que veio a liderar, no âmbito da comunidade científica, o movimento pela reforma global da universidade de forma a ampliar as suas condições de trabalho e promover um avanço científico mais sólido

8 A esse respeito, cumpre destacar a estreita vinculação de Anísio Teixeira com a SBPC, da qual, inclusive, foi presidente, durante dois mandatos consecutivos, de 1955 a 1957.

9 A respeito da CosupI, importa assinalar que seu criador foi Ernesto de Oliveira Júnior, que integrara a Comissão inicial da CAPES, como representante da Comissão Nacional de Assistência Técnica. Criada oficialmente em 1960, em 1958, a Comissão já dispunha de verbas gigantescas, se comparadas com o orçamento da CAPES. Cumpre, também destacar, que no momento de criação da COSUPI, se dá uma significativa redução das verbas do PQTC da CAPES. 
a médio e longo prazo. Este, aliás, foi o grupo que se articulou, junto a Darcy Ribeiro e Anísio Teixeira, em torno ao projeto original da Universidade de Brasília, que GUSSO, CÓRDOVA e LUNA (1985) caracterizam como a derradeira tentativa de reforma prática da universidade, que será levada a cabo pelo próprio governo, mas num momento já de agudização da crise política que irá desembocar no golpe militar de 1964 e no conseqüente desmantelamento do projeto. $^{10}$

\section{(Re)construir a universidade, formando o professor}

Em trabalho postumamente publicado, intitulado Ensino Superior no Brasil: análise e interpretação de sua evolução até 1969 (TEIXEIRA, 1989), Anísio Teixeira, partindo de uma retrospectiva histórica do ensino superior no Brasil, faz uma análise crítica da reforma universitária que então se iniciava com o processo de reestruturação das universidades federais.

Duas idéias fortes de Anísio Teixeira pretende-se destacar aqui, que apontam para questões pouco presentes na reflexão que usualmente se desenvolve sobre o ensino universitário.

Anísio Teixeira tinha uma sólida convicção, claramente expressa em vários dos seus textos-chave ${ }^{11}$, de que nenhuma mudança profunda se implantaria em qualquer tipo de escola - também e talvez principalmente na

10 Darcy Ribeiro foi coordenador da Divisão de Estudos e Pesquisas Educacionais do Centro Brasileiro de Pesquisas Educacionais (CBPE), órgão criado por Anísio Teixeira no interior do INEP, de 1957 a 1961, quando assumiu a reitoria da Universidade de Brasília. O CBPE foi um centro de pesquisas que procurava articular educadores e cientistas sociais no estudo dos problemas educacionais de forma a subsidiar as políticas públicas na área. A Universidade de Brasília foi concebida no interior do CBPE e da CAPES, com a colaboração de algumas das lideranças mais expressivas da SBPC, que integraram a Comissão encarregada da elaboração do projeto da universidade.

11 A meu ver, existem determinados textos de Anísio que se constituem em textos-chave para a compreensão do seu pensamento. Alguns desses textos são significativamente publicados pelo próprio Anísio Teixeira em diferentes fontes. Entre eles se inclui o texto A duplicidade da aventura colonizadora na América Latina e sua repercussão nas instituições escolares (TEIXEIRA, 1999), também publicado com o título Valores proclamados e valores reais nas instituições escolares brasileiras (TEIXEIRA, 1962), onde me parece que as idéias aqui destacadas aparecem expressas com mais clareza. 
universidade - por força de lei. Para ele, o formalismo legal era o mal dos males da educação brasileira, que estaria na origem da fraude e da dissimulação, características da forma como se deu a expansão do ensino, particularmente o secundário e superior entre nós (TEIXEIRA, 1999). É por isso que, ao se referir às mudanças que era preciso imprimir à universidade, este educador propugnava por uma reforma a partir de dentro, que exigiria, a seu ver, uma mudança radical nas práticas pedagógicas desenvolvidas no seu interior.

Sob esse aspecto, Anísio Teixeira defendia a necessidade de se implantar nesta instituição uma nova cultura acadêmica que deveria ser norteada, entre outras coisas, pela instauração de uma relação diferenciada dos professores entre si e entre alunos e professores. A instauração desse novo tipo de relação implicaria, antes de mais nada, na disseminação de uma cultura mais colaborativa na universidade, adequada aos princípios democráticos, que, para o educador, não se constituem em algo institucional e externo às pessoas, mas se expressam nas suas ações e atitudes cotidianas.

Além disso, exigiria também mudanças significativas no próprio conteúdo da formação universitária. Desse ponto de vista, para Anísio Teixeira, a universidade deveria passar a oferecer, nos seus diferentes cursos, uma formação simultaneamente teórica e prática, nos quais se privilegiaria muito mais a lógica do estudo e da investigação científica do que a lógica da aula expositiva.

Tais mudanças, para o educador, não se concretizariam, entretanto, sem profundas alterações na mentalidade dos professores universitários, implicando um enorme investimento na sua formação.

Para Anísio Teixeira, a verdadeira (re)construção da universidade brasileira não se faria, de forma alguma, sem esse investimento, e essa é uma das razões pelas quais este educador se mostrava profundamente cético com relação à reforma universitária que então se anunciava.

Ao se referir à inexistência entre nós de uma tradição universitária uma das deficiências estruturais do nosso ensino superior - Anísio Teixeira não se restringia a uma questão meramente organizativa, mas apontava para uma série de aspectos que estariam ao nível das práticas hegemônicas no interior das instituições de ensino.

Para ele, não só a tradição dominante do nosso ensino superior era a de escolas profissionais isoladas, mas essas escolas, todas elas de tempo parcial, consistiam meramente de " "aulas' de uma relação de matérias [...] ensinadas isoladamente e sem nenhuma conexão entre elas", já que "entre os professores [...] não havia entendimentos nem reuniões" (TEIXEIRA, 1989, p. 89).

Partindo dessa premissa, Anísio Teixeira traçava um quadro nada dis- 
tante do que são ainda hoje as práticas desenvolvidas no interior da imensa maioria das nossas instituições de ensino superior:

Geralmente, as aulas em cada matéria eram três por semana. Além das aulas, o único outro recurso didático era o de exames e, por vezes, provas parciais.

É evidente que semelhante método de ensino, sem dizê-lo expressamente, apoiava-se numa filosofia de auto-aprendizagem, competindo ao professor expor a matéria, se possível, clara e estimulantemente, e ao aluno estudar por si e sem auxílio do mestre, que apenas podia aplaudilo, ou recusá-lo nos exames. Geralmente, o aluno não tinha, também, qualquer convívio organizado com o outro aluno, havendo alguns que procuravam estudar juntos, mas quase sempre nas vésperas dos exames ou provas (TEIXEIRA, 1989).

Anísio Teixeira continuava assinalando que esse processo didático, dominado pelo autodidatismo, com o recurso ao livro, era ainda mais empobrecido com o "uso das sebentas ou apostilas, contendo resumos ou textos das aulas". E desta perspectiva, se posicionava particularmente contrário à idéia corrente de que o ensino superior se reduziria a aulas expositivas, criticando a própria noção de crédito, introduzida à época no ensino superior pelas instruções do Conselho Federal de Educação, que excluía expressamente da contagem das horas de trabalho o tempo de estudo individual do aluno.

Nas suas próprias palavras:

A exclusão é surpreendente, mas indica o grau em que o educador brasileiro julga o ensino superior como o equivalente ao primário, sendo a aula o real período de trabalho escolar e, portanto, o ensino ainda oral, podendo-se até prescindir do livro a ser substituído pela apostila, sucessora das velhas sebentas da Coimbra medieval (TEIXEIRA, 1989, p. $131)$.

E o educador expressava, desta forma, em 1969, o seu ceticismo diante da reforma que se propunha: 
Meu receio ante a nova estrutura planejada está em que não vejo a necessária ênfase no novo professor e no novo aluno que a nova universidade impõe. A simples mudança de estrutura sem a renovação de programas, de métodos, de professores e de alunos pode vir a deixar tudo no mesmo, embora os nomes e a disposição das coisas ou elementos da situação sejam diferentes (TEIXEIRA, 1989, p. 138).

Que novo professor seria esse, que Anísio Teixeira tinha em mente?

Esse novo professor, antes de mais nada, teria que ser dotado do que o educador chamava de espírito de pesquisa. A incorporação desse espírito de pesquisa não significava, entretanto, para ele, que todo professor universitário tivesse necessariamente que ser um pesquisador tout court. Anísio Teixeira, aliás, criticava a confusão que, a seu ver, se estabelecia na reforma que então se implantava entre ensino e pesquisa, sob a bandeira de uma pretensa integração.

Para ele, existiria ensino e existiria pesquisa, e não seria possível afirmar que todo ensino fosse pesquisa. E a pós-graduação é que se constituiria, sem dúvida, no lugar, por excelência, da prática de pesquisa na universidade. De qualquer forma, essa pesquisa, entendida enquanto a criação de um conhecimento novo, oxigenaria e revigoraria as aulas da graduação, mesmo que não fosse ali produzida ${ }^{12}$.

Por outro lado, afirmava Anísio Teixeira, "os métodos de ensino podem ser assimilados aos métodos de pesquisa, correspondendo isto a conduzir o estudante a adquirir o conhecimento já existente como se tivesse que o descobrir" (TEIXEIRA, 1989, p. 145). E esta se configuraria como a verdadeira chave para transformar a universidade em uma universidade de pesquisa, não bastando, portanto, para isso, simplesmente anexar à universidade a tarefa de pesquisa, como mais uma atribuição, um acréscimo. Nas palavras de Anísio Teixeira, "a universidade somente será de pesquisa quando passar a reformular a cultura que vai ensinar, porque a cultura humana tem de ser reelaborada para ser ensinada" (TEIXEIRA, 1989, p. 145).

12 É interessante assinalar que Anísio Teixeira, no trabalho que se está citando, chegava a propor uma forma de participação dos alunos de graduação nos projetos institucionais de pesquisa, bastante próxima à atual iniciação científica. 
...se desejo transmitir uma cultura nova, não a posso transmitir pondo o aprendiz em contato com os produtos dessa cultura, mas tornando possível ele aprendê-la pelo processo de sua formação, de modo que ele, de algum modo a reinvente, inserindo-a em seu modo de pensar. Ele não deve ficar apenas capaz de compreendê-la, mas de fazê-la e continuá-la, sem mencionar a capacidade de aplicá-la (TEIXEIRA, 1989, p. 100-101).

É nesse espírito e para essa tarefa que o professor universitário teria que ser formado. Esse o novo professor que se fazia necessário para uma universidade de fato reformada, ou melhor, reconstruída.

Não se pode esquecer, como já se disse anteriormente, que a reforma universitária idealizada por Anísio Teixeira deveria partir de dentro da própria universidade, não se reduzindo ao nível nem das simples declarações, nem das meras mudanças da sua maquinaria administrativa e organizacional. Teria que se constituir em uma aspiração dos professores que, ao transformarem a sua mentalidade e a de seu aluno por meio da aceitação do método científico, assumiriam a ciência experimental como o guia de suas ações.

Para essa mudança de mentalidade, a pós-graduação, enquanto o espaço por excelência da formação do professor universitário, cumpriria um papel preponderante. Atuando como uma verdadeira escola de formação de mestres, ao fabricar um novo habitus ${ }^{13}$ intelectual, transformaria o próprio cotidiano acadêmico, engendrando uma nova maneira tanto de ensinar quanto de pesquisar. Daí todo o empenho que Anísio Teixeira colocava na sua institucionalização entre nós.

\section{Um balanço final}

Das duas instituições criadas por Anísio Teixeira nos anos 1950/1960, o CBPE e a CAPES, é esta última que consegue sobreviver à sua ausência. ${ }^{14} \mathrm{O}$

13 De acordo com o conceito de BOURDIEU (1989).

14 Em 1964, Anísio Teixeira é demitido, a bem do serviço público, de todos os cargos que ocupava, pelo governo militar que se instala no Brasil. 
CBPE vai sofrer um processo de esvaziamento (que, na verdade, já se inicia anteriormente) $)^{15}$, que culminará com a sua melancólica extinção em 1968. A CAPES se fortalecerá após 1964, entre outras coisas, incorporando contraditoriamente a COSUPI, após um momento inicial em que se chegou a pensar igualmente na sua extinção.

A idéia que pretendemos desenvolver aqui é de que a CAPES, nos seus anos iniciais, e por meio dela, Anísio Teixeira, tiveram um papel fundamental no processo de institucionalização da pós-graduação na universidade brasileira. Quando se regulamentaram os cursos de pós-graduação no Brasil, em 1965, já em pleno governo militar, esta já tinha existência de fato, entre nós. A esse respeito, é significativa a observação de Almir de Castro, Diretor de Programas da CAPES de 1954 a 1964 (CASTRO, s d), de que, sem nenhum plano mirífico, qüinqüenal, quadrienal, o programa imediato da CAPES visava, sem dúvida, à promoção de cursos pós-graduados no país, de todo tipo, sem cogitação imediata de sua ordenação e regulamentação. Nas suas palavras, essa ordenação viria depois, com a participação decisiva, inclusive, de professores direta ou indiretamente vinculados à CAPES, enquanto membros do Conselho Federal de Educação (CFE).

Para isso, certamente colaboraram as políticas desenvolvidas pela CAPES de 1951 a 1964. Tais políticas nos permitem ir muito além da caracterização da CAPES como um órgão meramente dedicado à concessão de bolsas de pós-graduação no exterior para estudantes brasileiros. Pelo contrário, desde o início constata-se a centralidade que assumia dentre as atribuições da CAPES a de "promover a instalação e expansão de centros de aperfeiçoamento e estudos pós-graduados no país" (Decreto n. ${ }^{\circ} 29.741$, art. 3. ${ }^{\circ}$, letra f). A preocupação com o cuidadoso levantamento dos centros já existentes, a proposta de criação dos Centros Nacionais de Aperfeiçoamento Pós-Graduado, previstos igualmente no Decreto n..$^{\circ} 29.741$, para os quais se canalizariam os recursos técnicos e financeiros e que teriam um efeito multiplicador no interior de uma rede que se propunha construir, o caráter dos projetos previstos pelo $\mathrm{PgU}$, que expressavam sempre a preocupação com a consolidação de centros nacionais de excelência, são particularmente expressivos da política que se procurava implementar. A esse respeito, foi significativo constatar a priorização, nos projetos de qualificação do pessoal destinado à carreira universitária, das universidades de São Paulo, Minas Gerais, Pernambuco, Rio de Janeiro e Rio Grande do Sul, não por acaso as universidades públicas 
de alguma forma articuladas com os Centros Regionais de Pesquisa do CBPE. A análise de uma das nossas fontes documentais mais significativas, o Boletim Informativo CAPES ${ }^{16}$, apontou-nos uma série de estratégias desenvolvidas pela CAPES, de irradiação, articulação e mobilização que iam na direção da constituição de um sistema nacional de formação de quadros superiores no país, articulado entre si e com os principais centros universitários e de pesquisa do exterior, e cuja centralidade aparece claramente destacada nos depoimentos de antigos colaboradores de Anísio Teixeira na CAPES ${ }^{17}$.

Na nossa perspectiva, a institucionalização da pós-graduação operou uma mudança profunda na universidade brasileira, tendo sobre ela um impacto mais efetivo do que a própria reforma proposta pelo governo militar. Do nosso ponto de vista, aliás, quando este governo se instala, o processo de modernização da universidade brasileira já se havia instaurado e se tornara, em parte, irreversível, apesar do impacto extremamente negativo que vão ter sobre ela as medidas repressivas tomadas pelo governo militar. Essa é, também, a posição defendida por CUNHA (1983) e por GUSSO, CóRDOVA e LUNA (1985).

Para Cunha, é preciso desmitificar a idéia de que o processo de modernização da universidade brasileira teria se iniciado apenas após 1964, sob a influência direta dos acordos MEC-USAID. Afirma ele:

$\mathrm{Na}$ verdade, quando esses convênios foram integrados, no âmbito do ensino superior, a modernização da universidade já era um objetivo aceito por diversas correntes de opinião, de esquerda e de direita. Assim, quando os assessores norte-americanos vieram, em 1967, para compor a Equipe de Assessoria ao Planejamento do Ensino Superior, não precisaram de muitos esforços para despertar o consenso que tinha sido produzido entre os universitários, pelos porta-vozes do desenvolvimentismo (CUNHA, 1983, p. 204-205).

16 Esta publicação constituiu-se no objeto da dissertação de Mestrado de um dos membros da equipe de pesquisa (GOUVÊA, 2001).

17 Foram particularmente importantes para nós o extenso depoimento de Almir de Castro, Diretor de Programas da CAPES de 1954 a 1964 e braço direito de Anísio Teixeira nessa empreitada, prestado em 1977, ao Programa de História Oral da Ciência do CPDOC, coordenado por Simon Schwartzman, e o depoimento de Celso Barroso Leite, também colaborador de Anísio Teixeira e posteriormente Diretor Executivo da CAPES, ao grupo da pesquisa no ano de 2000. Estes depoimentos nos permitiram, particularmente, uma aproximação à dinâmica interna de funcionamento da instituição à época. 
De um outro ponto de vista, GUSSO, CóRDOVA e LUNA (1985) também afirmam que, "não obstante o estiolamento das mobilizações e projetos" desenvolvidos ao longo dos anos 1950/1960, o processo de mudança da universidade brasileira estava desencadeado e se tornaria "irreversível em seus eixos fundamentais de desenvolvimento". Por essa razão, para os autores, o novo regime implantado em 1964, após uma primeira fase repressiva e obscurantista, se veria "compelido a retomar o dinamismo das políticas de desenvolvimento científico-tecnológico, ainda que sob limitações políticas evidentes" (p. 143).

Essas limitações, do nosso ponto de vista, vão, entre outras coisas, condicionar uma reorientação dos investimentos, com uma forte priorização das áreas técnico-científicas. Dessa perspectiva, cumpre destacar, de maneira a fazer um contraponto, a preocupação da CAPES, nos seus anos iniciais, com um desenvolvimento equilibrado das diferentes áreas do conhecimento que se expressava nos projetos desenvolvidos. CASTRO (1977), em seu depoimento ao CPDOC, destaca a ênfase atribuída pela CAPES às Ciências Sociais, afirmando:

...nós (da CAPES) não achávamos que o desenvolvimento era uma coisa estanque, que se atendia apenas com tecnologia, com ciências básicas etc. Sabíamos que há um contexto de implicação e interação de todas as coisas e por isso mesmo, atendíamos também áreas como Ciências Sociais, que era uma área abandonada. A CAPES foi a primeira agência do governo a se preocupar com Ciências Sociais... (p. 6)

A esse respeito, é também significativa a observação de CÓRDOVA (1998), quando, referindo-se ao perfil da CAPES nos anos em estudo, assevera que este: "iniciado com 'quadros técnicos e científicos', foi incorporando, no discurso do Secretário Geral e na prática de operação do órgão, a dimensão das Artes, configurando-se, de fato, como 'quadros técnicos, científicos e artísti$\cos "$ " (p. 45).

Esta posição é, sem dúvida, coerente com a visão que Anísio Teixeira tinha, à época, do processo de desenvolvimento nacional, que de forma alguma se reduzia a uma dimensão meramente econômica, implicando mudanças de ordem social e, mesmo, cultural na sociedade brasileira.

Do nosso ponto de vista, após 1964 não era mais possível ao governo federal refrear o processo de transformação da universidade, seja pela pres- 
são exercida pelas classes médias no sentido da ampliação da oferta, que se traduzia na complicada questão dos excedentes ${ }^{18}$, seja pelas próprias necessidades do projeto de desenvolvimento econômico que se pretendia implementar no país. Não é, portanto, de forma alguma gratuito o fato de que o governo militar tenha começado a reorganização do sistema educacional pelo ensino superior, assumindo a liderança do seu processo de modernização. Já em 1966 seriam emitidos os dois decretos-lei que encaminhavam a reestruturação das universidades federais, incorporando várias das medidas ensaiadas nas experiências universitárias desenvolvidas nos anos 1950/1960 e prenunciando a reforma global do sistema.

O que se pretende ressaltar aqui é que, nesse processo de modernização da universidade brasileira que se inicia nos anos 1950/1960, a institucionalização da pós-graduação teve um papel absolutamente central, ainda pouco trabalhado nos estudos que se debruçam sobre a problemática universitária, no período em estudo. E, dessa perspectiva, a estratégia pensada por Anísio Teixeira de reconstruir a universidade brasileira pela pós-graduação, mesmo que contraditoriamente, foi relativamente bem sucedida, particularmente no que se refere à universidade pública. Especialmente nas universidades públicas, a pós-graduação disseminou-se, ao longo dos anos 1970/ 1980, de forma até surpreendente, garantindo que a pesquisa científica se desenvolvesse no âmbito dessa instituição e configurando-se progressivamente como o espaço de formação do professor universitário (até pelas próprias exigências formais que começaram a ser impostas pela carreira docente universitária).

18 Consideravam-se excedentes os candidatos inscritos nos exames vestibulares - de acesso aos cursos superiores - que excediam o número de vagas oferecidas. Esse problema foi se agravando ao longo dos anos 1950/1960, tendo em vista o crescente descompasso entre o aumento da demanda e a ampliação do número de vagas oferecidas nas instituições de ensino superior, que se deu em um ritmo muitíssimo mais lento. 


\section{REFERÊNCIAS}

BOURDIEU, P. O poder simbólico. Lisboa: Difel, 1989.

CASTRO, A. Um sopro das brisas dos cincoenta: a CAPES de Anísio Teixeira.[S.1.: S.n., 19-].

. Acervo de depoimentos sobre a História da Ciência no Brasil. Rio de Janeiro: Finep/CPDOC/FGV, 1977.

CÓRDOVA, R. A. CAPES: origem, realizações, significações. Brasília: CAPES, 1998. v. 1 .

CORRÊA, M. História da Antropologia no Brasil (1930-1960). São Paulo: Unicamp, 1987.

CUNHA, L. A. A universidade crítica: o ensino superior na República Populista. Rio de Janeiro: F. Alves, 1983.

GOUVÊA, F. C. F. Um percurso com os boletins da CAPES: a contribuiçaõ de Anísio Teixeira para a institucionalização da Pós-Graduação no Brasil. Rio de Janeiro, 2001. Dissertação (Mestrado) - Departamento de Educação, PUC-RJ.

GUSSO, D. A.; CORDOVA, R. A.; LUNA, S. V. A pós-graduação na América Latina: o caso brasileiro. Brasília: Unesco/Cresalc, MEC/Sesu/Capes, 1985.

MENDONÇA, A. W. P. C. (Org.). A formação dos mestres: a contribuição de Anísio Teixeira para a institucionalização da pós-graduação no Brasil (Relatório Final da Pesquisa). Rio de Janeiro: Departamento de Educação da PUC-RJ.

. Anísio Teixeira e a Universidade de Educação. Rio de Janeiro: Eduerj, 2002.

TEIXEIRA, A. S. Valores proclamados e valores reais nas instituições escolares brasileiras. Revista Brasileira de Estudos Pedagógicos, v. 37, n. 486, 1962.

. Ensino superior no Brasil: análise e interpretação de sua evolução até 1969. Rio de Janeiro: FGV, 1989.

Educação no Brasil. 3. ed. Rio de Janeiro: UFRJ, 1999.

VELHO, G. Projeto e metamorfose: antropologia das sociedades complexas. Rio de Janeiro: Zahar, 1994.

XAVIER, L. N. O Brasil como laboratório: educação e ciências sociais no projeto do Centro Brasileiro de Pesquisas Educacionais CBPE/INEP/MEC (1950-1960). Bragança Paulista: Ifan/CDAPH/Edusf, 1999.

Texto recebido em 19 jan. 2003

Texto aprovado em 19 fev. 2003 